\title{
Exit exam for interns: Lessons learnt and challenges for the future
}

\author{
Susan Solomon ${ }^{1, *}$, Sheela Devi C. ${ }^{2}$, Thomas Alexander ${ }^{3}$, Renu G'boy Varghese ${ }^{4}$ \\ Professor, ${ }^{1}$ Dept. of Psychiatry, ${ }^{2}$ Dept. of Microbiology, ${ }^{3}$ Dept. of Gastroentology, ${ }^{4}$ Director Principal, Pondicherry Institute of \\ Medical Sciences, Kalapet, Puducherry, India
}

*Corresponding Author:

Email: susanjsolomon@gmail.com

\begin{abstract}
Introduction: India has witnessed a steady rise in the number of medical colleges in the last two decades. Despite fears about the quality of medical education, the competency of the graduates is not usually assessed by an objective examination at the end of internship.

Aim: The aim was to assess the knowledge, skill and attitude levels of interns of a 15 year old private medical college by conducting an exit exam, after completion of internship.

Material and Methods: Eighty interns took the exam which was in an OSCE (Objective Structured Clinical Examination) format. There were 12 stations for assessment of knowledge and eight supervised stations for assessment of skills and attitude. All the questions were from the 'must know' areas and covered common clinical conditions and emergencies.

Results: The average marks obtained by the interns in the knowledge and skill round were $48.5 \%$ and $49.5 \%$ respectively. Overall only $45 \%$ of the interns responded correctly to at least $50 \%$ of the 'must know' areas.

Conclusion: There is an urgent need to reevaluate the teaching-learning process in order to produce doctors who are competent to function as physicians of first contact.
\end{abstract}

Keywords: Exit exam, Interns.

\section{Introduction}

India produces more doctors than any other country in the world. The number of medical colleges in the country continues to be on the rise, with a current total of $462 .{ }^{1}$ Coupled with this increase in the number of colleges, are the factors of inadequate infrastructure, lack of committed faculty, insufficient patient load and poorly motivated students. In varying combinations, all of these factors often lead to the passing out of a medical graduate without the necessary knowledge, skills and attitude. The period of Internship is crucial for acquisition of not only clinical skills but also communication and managerial skills that are necessary for a practicing doctor as laid out by the Medical Council of India (MCI). However, this period is underutilized by the interns for a number of reasons. The limited number of post graduate seats drives the interns to use this period to prepare for postgraduate exams. ${ }^{2,3}$ Internship period also suffers from lack of supervision compounding the problems further. ${ }^{2,4}$ Therefore interns lose opportunities to acquire basic skills necessary for practice.

Assessment of interns has been a felt need. ${ }^{2}$ Such an assessment would enable us to evaluate the undergraduate teaching learning process and make necessary changes in the educational process. Keeping this objective in mind, we conducted an exit exam for the interns in our institution as a tool to evaluate the outcome of our undergraduate training program.

\section{Material and Methods}

The exam was conducted on two consecutive days in December 2015, with a different set of questions on each day. A total of eighty interns belonging to the 2010 batch completed the examination. All the questions were in an OSCE format and from 'must know' areas. There were 12 stations for assessment of knowledge with two questions each from Medicine, Orthopedics and Pediatrics and three each from Obstetrics and Surgery. Eight stations were allotted for assessment of clinical skills. The students were allotted four minutes for each station and each station carried a maximum of five marks.

The skill round was observed by the concerned faculty and it tested the following areas: resuscitation basic life support, arrhythmia detection and management, suturing, male catheterization, auscultation of cardiovascular and respiratory systems, communication, measuring pulse and blood pressure. The last skill was added keeping in mind that interns should not take such an extremely basic yet vital skill for granted and commit mistakes. Appropriate manikins were used for the skill round stations except the communication station. Communication skills were assessed at two stations and consisted of taking informed consent for a minor procedure and breaking bad news. Trained members of the faculty enacted the clinical scenario and the students' performance was assessed by faculty from the department of Psychiatry using a checklist. Interns were not given prior information about the exam whereby studying in the last minute was avoided and a realistic estimate of their knowledge and skills was made possible. Intermingling of students before the completion of both rounds was prevented. At the end of the exam, an open-ended anonymous feedback was obtained from them. 


\section{Results}

Table 1 shows the marks obtained in the knowledge and skill round. The pass percentage in the exam is given in Table 2. A score of $50 \%$ and above was considered as having passed, though this is not the least bit ideal since all the questions were only from the 'must know' areas.

In particular, pulse rate was measured accurately by only $66 \%$ of the candidates, systolic blood pressure by $65 \%$ and only $43 \%$ measured the diastolic blood pressure accurately. This was after giving a leeway of +/- 10 for pulse rate and blood pressure (systolic and diastolic).

Anonymized feedback obtained from the interns at the end of the exam was generally positive with regard to the conceptualization and execution of the exit exam.
Interns felt it was useful because it enabled them to recognize their deficiencies and recommended it for the future batches of interns. Some suggested that such an exam be conducted at the end of each posting and that they needed more training in clinical skills especially in the areas of resuscitation and communication. They felt that clerical work took up a substantial portion of their valuable time during internship, which could otherwise have been devoted to skills training.

The faculty of the department of medical education of the institute provided face to face feedback about the results to all the departments involved and earnestly requested them to recommend and implement the much needed changes in the teaching-learning process for the upcoming batches of students and interns.

Table 1: Marks obtained in the knowledge and skill round

\begin{tabular}{|l|c|c|c|c|}
\hline Marks obtained & Average & $\begin{array}{c}\text { Maximum } \\
\text { mark }\end{array}$ & $\begin{array}{c}\text { Minimum } \\
\text { mark }\end{array}$ & $\begin{array}{c}\text { Total } \\
\text { marks }\end{array}$ \\
\hline Knowledge round & $29.1(48.5 \%)$ & $46(77 \%)$ & $10.5(18 \%)$ & 60 \\
\hline Skill round & $19.8(49.5 \%)$ & $34(85 \%)$ & $8.25(21 \%)$ & 40 \\
\hline Overall & 48.9 & $68.5 \%$ & $20.25 \%$ & 100 \\
\hline
\end{tabular}

Table 2: Pass percentage in the knowledge and skill round

\begin{tabular}{|l|l|}
\hline Knowledge round & $51 \%$ \\
\hline Skill round & $45 \%$ \\
\hline Overall pass percentage & $45 \%$ \\
\hline
\end{tabular}

\section{Discussion}

India has witnessed a rapid growth in the number of medical colleges in the last 20 years. In this quest for increased numbers of doctors there have been increasing concerns about the quality of medical graduates. Multiple factors including poor infrastructure, insufficient numbers of committed faculty, poor patient load and poorly motivated students hamper the fulfillment of the MCI goal of creating a basic doctor who has the requisite knowledge, skills, attitudes, values and responsiveness to function as physicians of first contact in the community. ${ }^{5}$

The assessment of competencies of medical graduates at the exit point has been a felt need since it would enable the stakeholders to obtain valuable feedback about the outcome of the teaching learning process. This would direct necessary changes to ensure that the graduates are competent to serve as physicians of first contact. With these objectives in mind, we conducted this (2015) exit exam for the interns in our institution. We had conducted a similar exit exam for interns in 2014, which was rather limited in scope because most of the manikins used in the present evaluation were then unavailable in our institution.

The faculty of the medical education department of our institution identified the areas that interns should be proficient in, on completing their medical training and before starting practice as physicians of first contact. These included identifying and treating emergencies, managing common clinical disorders, resuscitation skills, and communication skills and performing basic procedures. Following this, the faculty of the concerned departments was asked to frame questions from these areas. It was emphasized that the questions should be from the 'must know' category and address both common clinical problems and emergencies.

The results of the interns' exit exam revealed that around $50 \%$ of our graduates did not correctly answer even $50 \%$ of the must know areas. The findings about the accuracy of pulse and blood pressure measurements further revealed the deficiency of the interns in such extremely basic yet important clinical skills. Our institution has over the years implemented several measures to achieve the goals specified by the Medical Council of India and beyond. The introduction of early clinical exposure, early internship exposure, student clerkship, practice of evidence based medicine and weekly sessions on medical humanities was done to mould the students into competent, skilled and caring professionals who would be lifelong learners. Despite these efforts, the results of the exit exam indicated significant deficiencies in the system. The way forward would be to move beyond university examinations and focus on common clinical problems. Students focus only on 'exam cases' such as cerebrovascular accidents, valvular heart disease, etc and do not acquire skills for managing more common clinical situations. Instituting a competency based training wherein key competencies are identified by each department for every posting and certification made mandatory before proceeding to the 
next academic level would be a good step, if implementable.

The Indian Medical Council amendment bill has proposed NEXT (National Exit Test) for all medical graduates for granting license to practice medicine and for admission to postgraduate courses. ${ }^{6}$ Such measures would certainly enhance student motivation to learn and perform better. However we feel that such an exam should test them on the 'must know' areas of the syllabus and also incorporate evaluation of essential skills This is no doubt extremely difficult given the ground reality and logistics, but otherwise many of the core elements of the profession would remain unevaluated.

Another important aspect which we wish to highlight is the discrepancy between the university assessment and ours. The entire batch of 80 interns had scored above $50 \%$ marks in the university exams and 34 had scored above $60 \%$ and 2 interns above $70 \%$.Yet the maximum mark in the knowledge round and skill round were $77 \%$ and $85 \%$ respectively, despite all the questions being from the must know areas! One major reason for this is that though participation in the exit exam was mandatory for all interns, its outcome had no bearing on them. There were neither penalties for a poor performance nor rewards for a good performance. Since the educational system at all levels in the country is linked to a rewards/penalties system, interns may not have 'bothered' to give of their best. We particularly feel that this may have been a major reason for the ineptitude displayed regarding pulse and blood pressure measurements. Additional limitations of our study include lack of standardization of the areas and questions covered in the exam. We however ensured that only important areas have been evaluated.

\section{Conclusion}

The exit exam for interns conducted in our institution revealed that there are deficiencies in the teachinglearning process resulting in the production of graduates who lack the requisite knowledge and skills to practice as physicians of first contact. The propose introduction of an exit exam at the national level may prove to be a valuable solution in creating doctors with the optimum amount of knowledge, skills and attitudes, provided the examination incorporates evaluation of all these elements.

\section{References}

1. Accessed from www.mciindia.org/InformationDesk/ForStudents/ListofC ollegesTeachingMBBS.aspx

2. Sood R, Adkoli BV. Medical Education in IndiaProblems and Prospects. JIACM 2000;1(3):210-13.

3. SupeA. Challenges and Issues in Medical Education in India. Acad Med 2006:81(12):1076-80.

4. Anantha krishnan N. Medical education in India: Is it still possible to reverse the downhill trend? Med Educ 2010;23(3):156-60.
5. Accessed from www.mciindia.org/tools/announcement/MCI_booklet.pdf

6. Accessed from niti.gov.in/content/draft-national-medicalcommission-bill-2016. 